\title{
BACTERIOLOGICAL STUDIES IN CROHN'S DISEASE
}

\author{
Angela Vince, N. H. Dyer*, F. W. O’Grady and A. M. Dawson \\ St Bartholomew's Hospital, London
}

AlTERED anatomy or motility of the small intestine may permit its colonisation by bacteria that interfere with the absorption of vitamin $\mathrm{B}_{12}$ and fat (Badenoch, 1958; Donaldson, 1964; Tabaqchali and Booth, 1967) or degrade dietary protein (Jones et al., 1968). Recognition of this possibility has led to a resurgence of clinical interest in the role of the intestinal bacterial flora. Crohn's disease offers rich opportunities for bacterial overgrowth, because it may be complicated by strictures, fistulae, post-operative stagnant loops, or enteroanastomoses. It has been assumed that overgrowth often occurs in this disease and plays a part in the genesis of the malabsorption and malnutrition (van Patter et al., 1954; Bockus, 1964) that is often present, but this assumption has not been supported by any extensive bacteriological study. Drasar and Shiner (1969) cultured juice from the upper jejunum in six patients and found bacterial overgrowth in only one whose disease was complicated by jejunal obstruction.

We therefore decided to study the bacterial content of aspirates from various levels of the gastro-intestinal tract of patients with Crohn's disease in an attempt to assess the frequency and significance of any differences from a group of normal controls.

\section{METHODS}

Subjects studied. Thirteen patients with Crohn's disease of varying anatomical distribution were intubated. They were chosen partly because of their willingness to undergo intubation and in some cases because the nature of their disease suggested possible bacterial overgrowth. Their age and sex, and the location of disease, are indicated in the table. The 20 control subjects were all medical staff or students with no evidence of gastro-intestinal disorder, and all except two were male. Preliminary findings indicated the possibility of a change in the salivary bacteriology of patients with Crohn's disease. To test whether this change was common to other chronic inflammatory disorders, the saliva of ten patients with active rheumatoid arthritis and ten patients with ulcerative colitis was examined.

Intubation of subjects. After an overnight fast, the subject swallowed an open-ended polyvinyl tube with an internal bore of $1.75 \mathrm{~mm}$ and weighted by 1-2 $\mathrm{ml}$ of mercury. Samples were obtained from the stomach and upper $10 \mathrm{~cm}$ of the jejunum. The tube was then allowed to progress down the bowel as the subject ate normally. Samples were taken from the lower jejunum or upper ileum (mid-intestine) when the tube had progressed to $160-200 \mathrm{~cm}$ from the teeth and its position had been checked by X-ray screening. Samples from the terminal ileum were collected next morning after an overnight fast. The position of the tube was checked radiologically and confirmed by the introduction of air or barium after the collections had been completed. These samples were always obtained from within $30 \mathrm{~cm}$ of the ileo-caecal valve or ileo-colic anastomosis, although the distance from the teeth was variable.

Received 23 Aug. 1971; accepted 1 Oct. 1971.

* Present address: Queen Elizabeth Hospital, Birmingham.

J. MED. MICROBIOL.-VOL. 5 (1972) 
Samples were obtained by gentle aspiration into a $20-\mathrm{ml}$ sterile syringe after a quantity equal to the capacity of the tube had been discarded. They were all delivered to the laboratory and examined within half an hour of collection. It was not technically possible to obtain samples from every site in each patient.

Bacteriological techniques. After the sample had been mixed in a micro-emulsifier, serial ten-fold dilutions of it were made and portions were plated on a wide variety of standard media and incubated aerobically and anaerobically as previously described (Hamilton $e t$ al.,

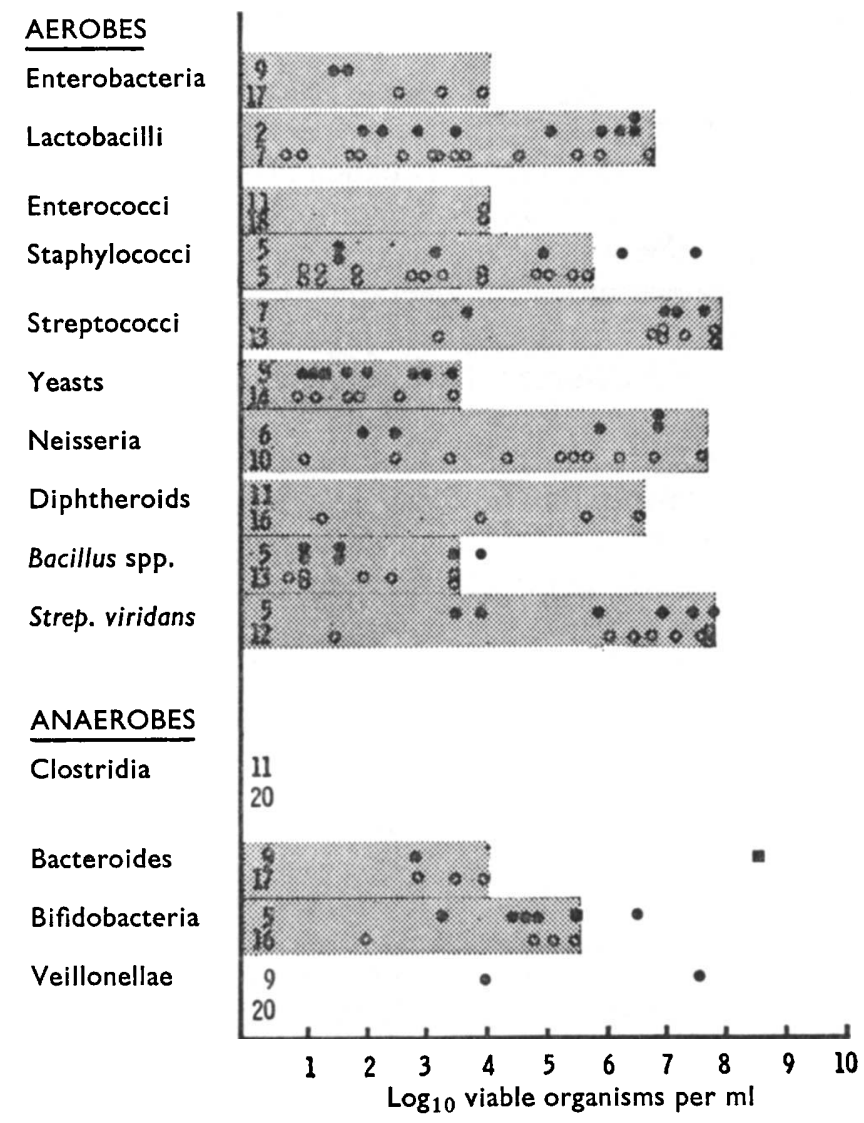

FIG. 1.-Bacteriology of gastric juice in 11 fasting patients with Crohn's disease ( $)$ compared with 20 normal controls $(O)$. The subject with the most significant abnormalities ( $\square$ ) had a duodenocolic fistula. The numbers on the left of the chart indicate the number of subjects from whom the indicated organism was not cultured. Normal ranges are indicated by the hatched area.

1970). Results are expressed as the $\log _{10}$ number of organisms per $\mathrm{ml}$ of fluid, or $\log _{10}$ number of organisms per $\mathrm{g}$ (wet weight) of faeces.

Metabolic investigations. Vitamin $\mathrm{B}_{12}$ absorption was measured by the method of Schilling (1953): $0 \cdot 5 \mu \mathrm{g}$ of ${ }^{58}$ Co-labelled vitamin $\mathbf{B}_{12}$ was given by mouth with two capsules of intrinsic factor, each containing not less than 1 USNF unit, and an intramuscular flushing dose of $1000 \mu \mathrm{g}$ of vitamin $\mathrm{B}_{12}$. Urine was collected for $24 \mathrm{hr}$.

Three subjects were given $1 \mu \mathrm{g}$ of labelled vitamin $\mathbf{B}_{12}$ with intrinsic factor orally and the radioactivity was estimated in the stools (Heinle et al., 1952).

Faecal fat was estimated by the method of van de Kamer, ten Bokkel Huinink and Weyers (1949) with the patient on a 100-g fat diet. Qualitative estimation of bile-salt deconjugation 
in the intestinal samples and measurement of urinary indican excretion were performed as described previously (Hamilton et al.).

\section{RESULTS \\ General bacteriological findings}

The bacterial flora at different levels of the gut in healthy subjects and in patients with Crohn's disease is indicated in figs. 1-4. The numbers of organisms

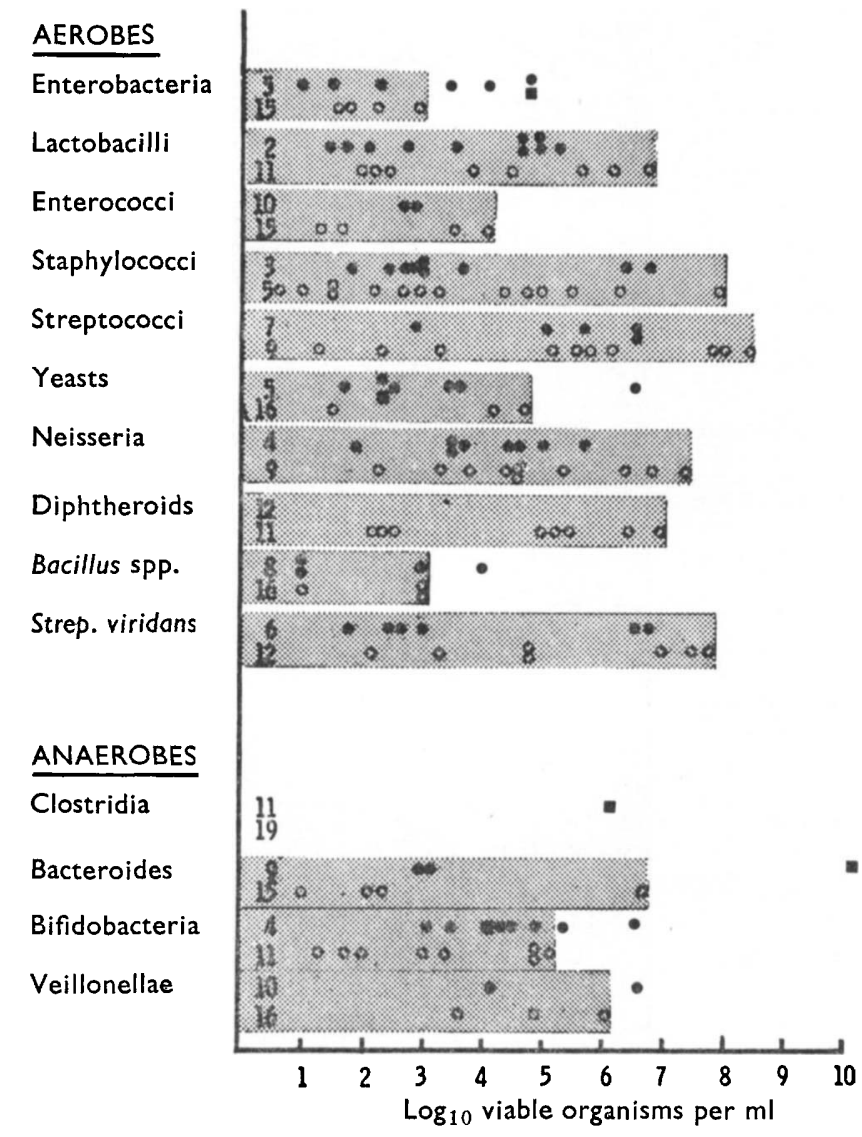

FIG. 2.-Bacteriology of the upper jejunal contents in 12 fasting patients with Crohn's disease compared with 19 normal controls. Symbols as in fig. 1.

recovered from the stomach of patients generally fell within the normal range, the only notable exception being in a patient (M. L.) who had a duodeno-colic fistula. In the upper jejunum, counts of enterobacteria were raised in four patients, increases in other organisms again being restricted to the patient with the duodeno-colic fistula. In the mid-gut, raised counts of several organisms were present in several patients. Organisms whose numbers were most often increased were enterobacteria, enterococci, yeasts, and lactobacilli. In the terminal ileum, many aerobes and anaerobes were found in healthy subjects in 
whom counts of enterobacteria, enterococci, lactobacilli, streptococci, yeasts, neisseria, and diphtheroids often equalled or exceeded those found in patients with Crohn's disease. Consequently it was difficult to define an abnormal flora in this region, though raised counts of anaerobes were found in some patients. The bacterial flora at any level was defined as abnormal if counts of

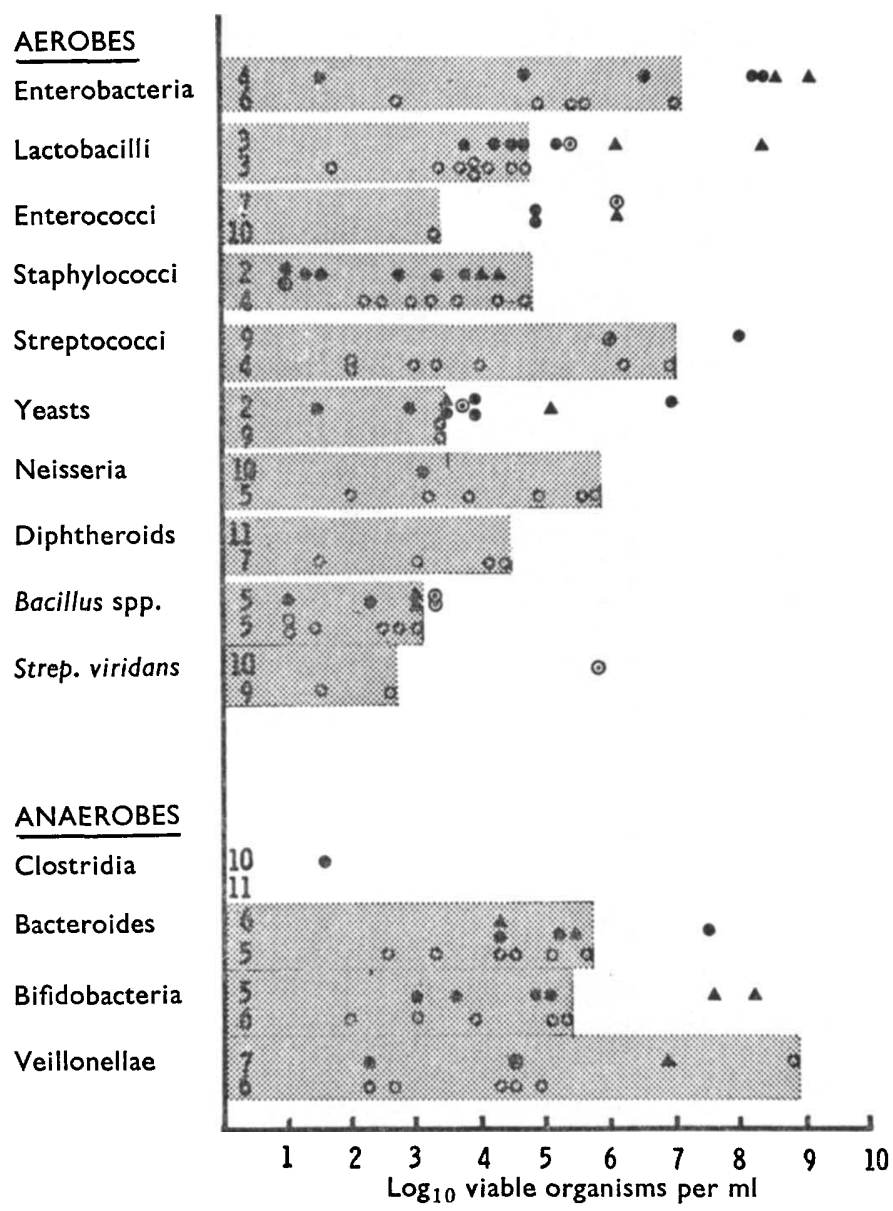

FIG. 3.-Bacteriology of the mid-intestine in 11 patients with Crohn's disease compared with 11 normal controls. $\boldsymbol{\Delta}=$ Patient with an ileal resection of more than $50 \mathrm{~cm} . \odot=$ Patient with an ileal resection of less than $50 \mathrm{~cm}$. Other symbols as in fig. 1 .

one or more of enterobacteria, enterococci, clostridia, or bacteroides exceeded those found in normal subjects by a factor of ten or more (table). On this basis, eight patients were judged to have some degree of overgrowth. In three (P. S., R. S., L. A.) the abnormality was confined to a small increase in a single species, so the finding was of doubtful significance. In the remaining five patients (M. H., H. P., M. L., J. U., S. F.) substantial overgrowth involved a wide variety of species, so that in these patients the findings were similar to those described in the stagnant-loop syndrome. 
In one patient (M. L.) overgrowth was clearly due to the presence of a fistula connecting sparsely and densely populated areas of the gut. The other four with overgrowth had extensive disease. Two (J. U., S. F.) had had much of the ileum resected, but still had segments with recurrent disease and radiological evidence of stasis. The other two (M. H., H. P.) had diffuse small-gut disease

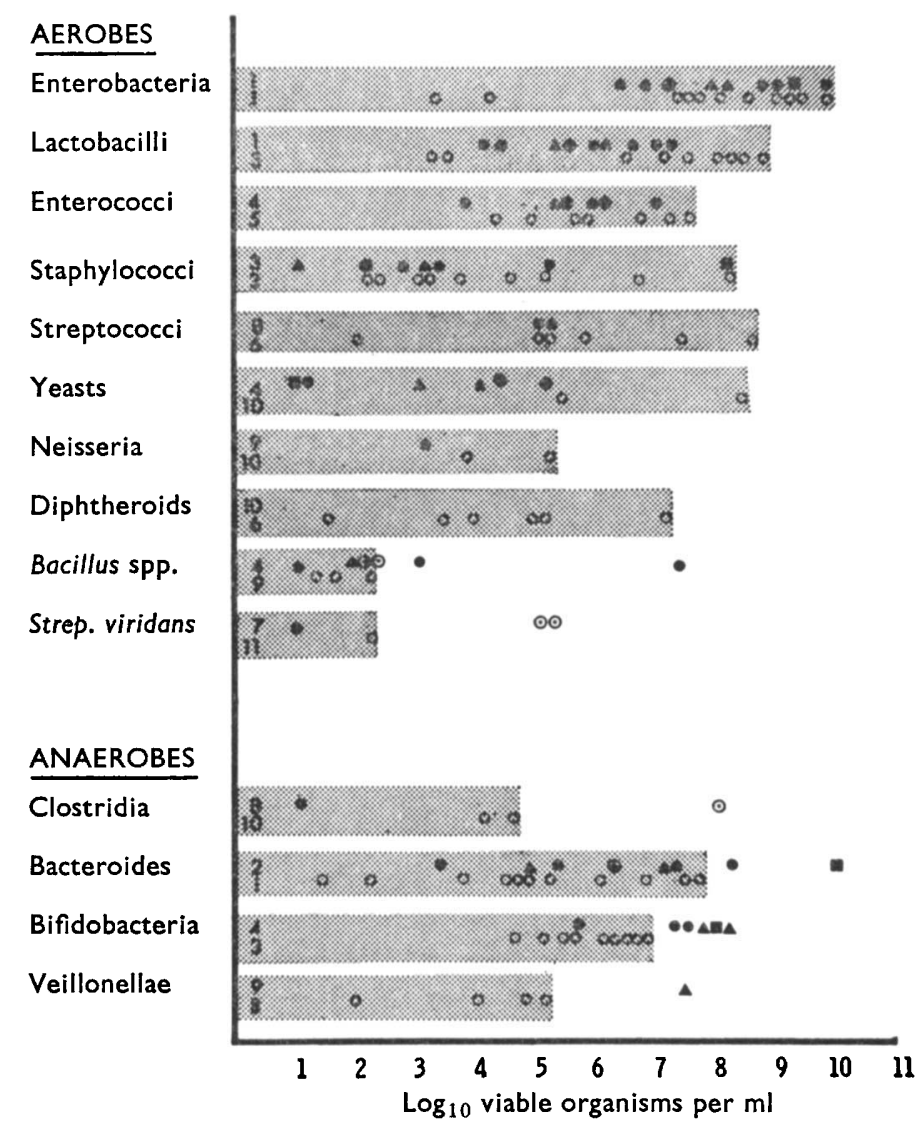

FIG. 4.-Bacteriology of the terminal ileum in ten patients with Crohn's disease compared with 12 normal controls. Symbols as in fig. 3. The two patients indicated by $\boldsymbol{\Delta}$ had had all the ileum removed so that samples, although coming from the distal intestine, were not true terminal ileal samples.

involving the jejunum and the ileum. In neither would the tube progress beyond the mid-gut, probably because of impaired peristalsis rather than stricture.

\section{Significance of the ileo-caecal valve}

In two of three patients in whom the ileo-caecal valve had been resected (L. A., S. A. S.), the small-gut flora resembled that found in normal subjects. In the third (J. U.) there was gross bacterial overgrowth, but this was no greater than that found in S. F. who had undergone ileal resection with preservation of the ileo-caecal valve. 
224 ANGELA VINCE, N. H. DYER, F. W. O'GRADY AND A. M. DAWSON

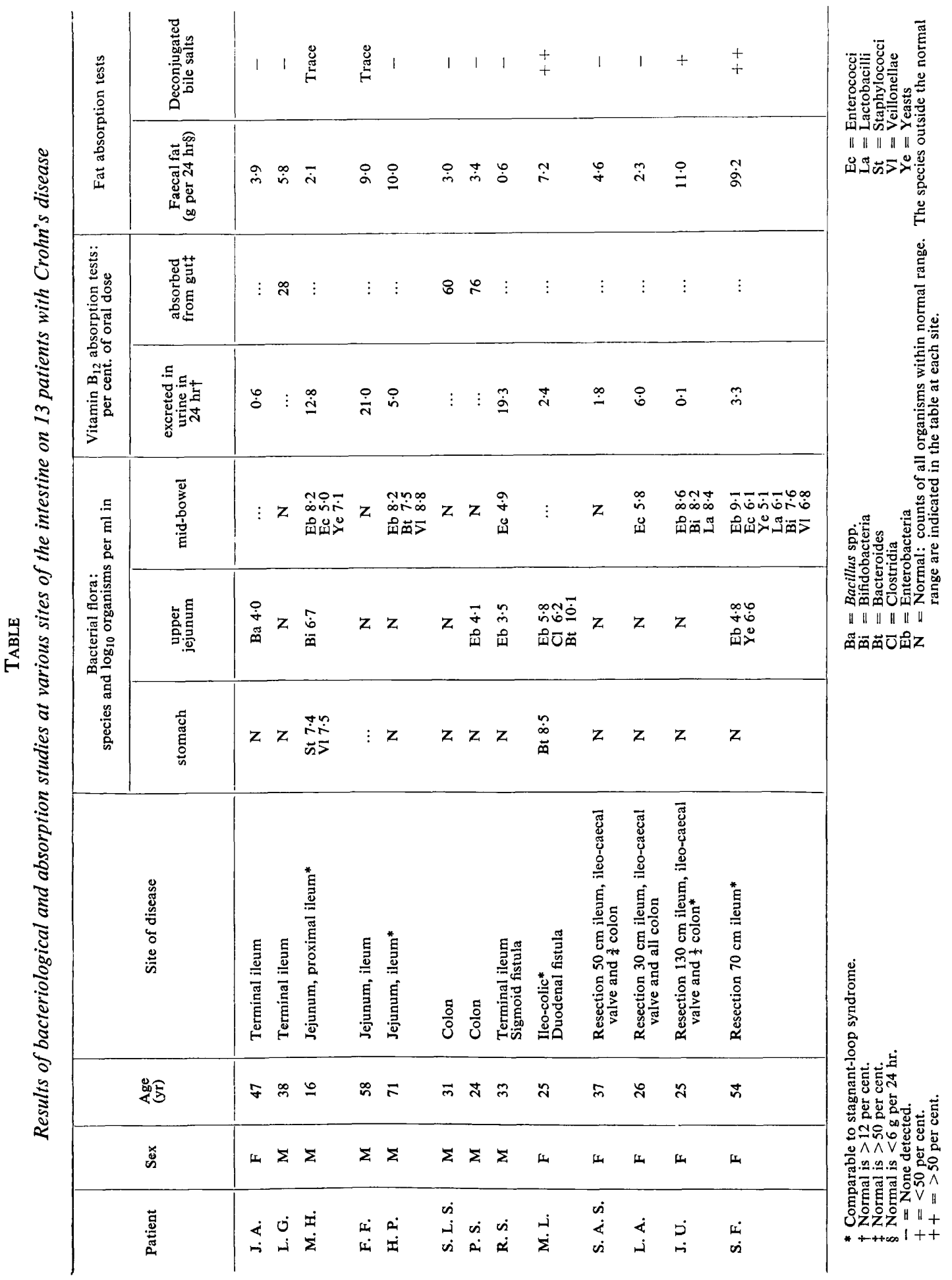




\section{Specific bacteriological findings}

There was a virtual absence of aerobic diphtheroids in patients with Crohn's disease (figs. 1-4). They were recovered from only one of 44 samples of gastroenteric juice from the patients, compared with 39 of 85 samples from healthy

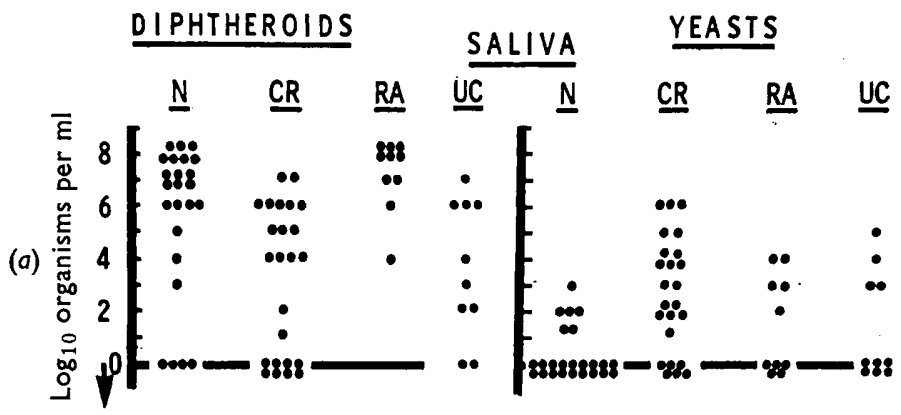

MID B OWEL
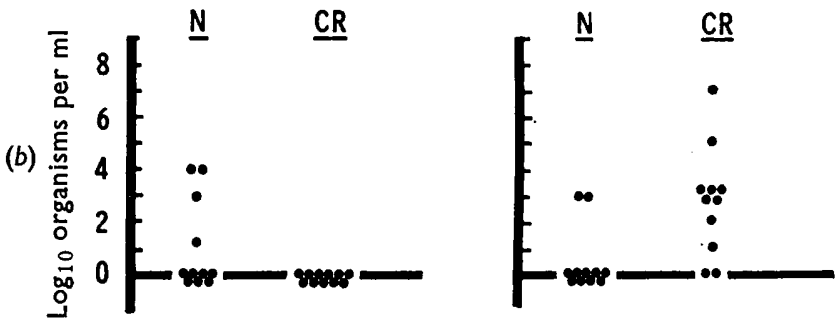

\section{FAECES}

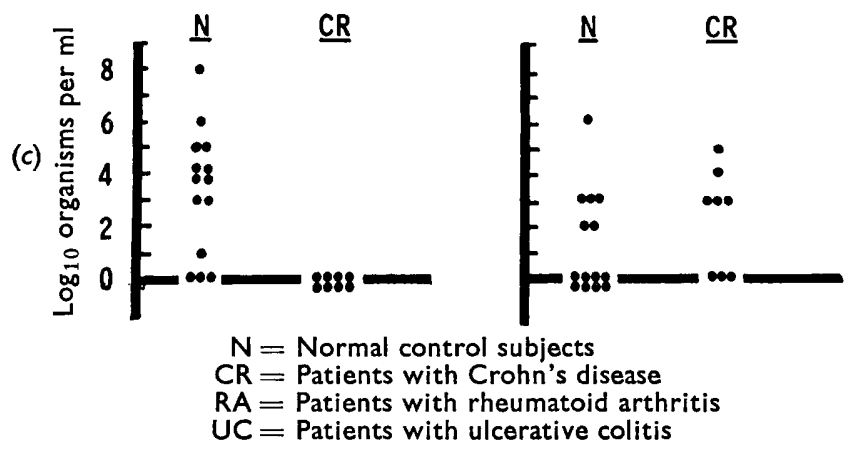

FIG. 5.-Diphtheroids and yeasts recovered from (a) the saliva of 24 normal subjects, 24 patients with Crohn's disease, ten patients with ulcerative colitis, and ten patients with rheumatoid arthritis, $(b)$ the mid-bowel of 11 normal subjects and 11 patients with Crohn's disease, and $(c)$ the faeces of 14 normal subjects and eight patients with Crohn's disease.

controls. This depression was evident even in salvia, from which diphtheroids were recovered less often and in smaller numbers from the patients than from healthy controls (fig. 5). The concentration of diphtheroids appeared to be similarly reduced in the saliva of patients with ulcerative colitis, but not of those with rheumatoid arthritis. 
In contrast to this depression of diphtheroids, higher counts of yeasts were noted in all parts of the gut sampled from patients with Crohn's disease. This increase was present but less marked in some patients with ulcerative colitis and rheumatoid arthritis.

\section{Vitamin- $B_{12}$ absorption}

Results from individual subjects are given in the table. Excretion of less than 12 per cent. of the dose of labelled vitamin $B_{12}$ (the lower limit of normal excretion) was found in eight patients. Four of these had undergone ileal resection and the other four had ileal disease, so in no case was it necessary to invoke bacterial overgrowth as the cause of malabsorption. Nevertheless, substantial overgrowth, including organisms that are thought to impair vitamin $\mathrm{B}_{12}$ absorption, was present in four of the eight subjects (H. P., M. L., J. U., S. P.). Another patient (M. H. )with substantial overgrowth and disease of the jejunum and proximal ileum (but not of the distal ileum-the site of vitamin $B_{12}$ absorption) absorbed vitamin $B_{12}$ normally.

\section{Faecal-fat excretion}

Results for individual subjects are given in the table. Only five of the 13 patients had steatorrhoea; four of these had undergone extensive ileal resection or had combined disease of the jejunum, where fat is absorbed, and of the ileum, where bile-salts are reabsorbed, which was sufficient to account for the finding. Increased counts of bacteroides, enterococci, and enterobacteria were found in four of these patients while in only two was there more than 50 per cent. splitting of conjugated bile salts. One patient (M. H.), who had gross contamination of the mid-bowel but no bile-salt deconjugation, did not have steatorrhoea.

\section{Antibiotic therapy}

Two patients (M. L., H. P.) were given tetracycline (500 mg q.d.s.) after organisms present in the upper gut had been shown to be sensitive to the agent in vitro. There was a reduction or elimination of some members of the anaerobic flora, but in both patients representation of aerobic organisms increased quantitatively and qualitatively. Both had impaired absorption of vitamin $\mathbf{B}_{12}$, which was not improved by tetracycline, possibly because both also had ileal disease.

\section{Discussion}

In healthy subjects the numbers and variety of organisms recovered from all levels of the bowel were greater than those reported by some previous workers (Shiner, Waters and Gray, 1963; Tabaqchali et al., 1966) but similar to those reported by others (Gorbach et al., 1967; Gorbach et al., 1969). Much less information is available about the microflora of the mid-gut and terminal ileum than of the upper small bowel. In agreement with Drasar, Shiner and McLeod (1969), we found that the numbers of organisms recovered increased as the small bowel was traversed. 
Mid-intestinal contents were aspirated at various levels, so conclusions must be tentative, but this region yielded more information about bacterial overgrowth than did terminal ileal intubation. In four of the patients studied, the flora would have been passed as normal if aspirates had been restricted to the stomach and upper jejunum, because overgrowth was apparent only in more distal parts of the small bowel. On the other hand, aspirates from the terminal ileum of normal subjects usually contained large numbers of organisms that were seldom exceeded in samples from similar areas in patients with Crohn's disease, making it almost impossible to define bacterial overgrowth. Study of the terminal ileum is therefore considered to be of limited value in the demonstration of small-gut overgrowth.

Crohn's disease is a difficult condition to study because disturbances of metabolism and bacteriology vary with the site of the disease. The high proportion of patients found to have some abnormality of the small-gut flora was to be expected in a disease characterised by inflamed or stenosed bowel or fistulae, but motility is undoubtedly important in maintaining the low bacterial population normal in the jejunum (O'Grady and Vince, 1971). Colonisation cannot occur at any site unless the rate at which organisms multiply or are supplied to the area exceeds the rate at which they are removed. This was confirmed by the finding that only patients with obvious stasis or a duodeno-colic fistula exhibited considerable overgrowth in the small gut. Those with comparatively normal gut-motility, or disease restricted to the terminal small bowel, did not show increased bacterial colonisation of the upper small gut.

The deficiency of diphtheroids and relative abundance of yeasts in this heterogeneous collection of patients is difficult to explain and could not be accounted for by recent antimicrobial or steroid therapy. The change is probably not a non-specific response to chronic inflammation or ill-health, as the same trends were not apparent in patients with rheumatoid arthritis. Reduced recovery of diphtheroids from the saliva of patients with ulcerative colitis suggests that there may be an association with inflammatory gut disease, but with so few specimens studied this speculation must remain tentative.

It proved impossible to demonstrate a coherent relationship between the absorptive and metabolic defects of patients with Crohn's disease and the presence of an abnormal bacterial flora. This study has shown that malabsorption of vitamin $\mathrm{B}_{12}$ usually depends more on disease or resection of the terminal ileum than on the presence of an abnormal flora. Disease or excision of the ileum in patients with Crohn's disease may explain why they differ from other patients with the blind-loop syndrome in whom the ileal absorptive areas are normal in failing to improve their vitamin $\mathrm{B}_{12}$ absorption after antibiotic therapy (Cameron, Watson and Witts, 1949; Mollin, Booth and Baker, 1957). Furthermore, patient M. H. confirms previous findings that gross contamination of the small gut by faecal-type organisms is compatible with normal vitamin $\mathrm{B}_{12}$ absorption (Paulk and Farrar,1964; Hamilton et al., 1970). Three patients who showed significant deconjugation of bile salts-which seems to be the governing factor in the production of steatorrhoea in the blind-loop syndrome (Tabaqchali, Hatzioannou and Booth, 1968)-had steatorrhoea but bacterial 
overgrowth, including species able to deconjugate bile salts, was not always associated with increased excretion of fat.

\section{SUMMARY}

The bacterial flora of aspirates from the stomach, the upper jejunum, the mid-gut, and the terminal ileum of 13 patients with Crohn's disease was compared with that obtained from similar sites in healthy subjects. The relationship of the bacterial flora to the site of disease and to the absorption of vitamin $\mathrm{B}_{12}$ and fat was examined.

Increased colonisation of the upper gut was seen only in patients with obvious stasis due to upper-gut disease, or when the upper and lower gut were connected by a fistula. In patients with comparatively normal motility, or in whom disease was restricted to the terminal small bowel, the flora was similar to that of healthy subjects. Aerobic diphtheroids were virtually absent from and higher counts of yeasts were present in all areas of the gut of patients with Crohn's disease.

No consistent relationship could be demonstrated between absorptive defects and the presence of an abnormal bacterial flora. Malabsorption of vitamin $B_{12}$ usually depended more on loss or disease of the terminal ileum than on increased numbers of bacteria in the small gut. Three patients who showed significant deconjugation of bile salts had steatorrhoea but bacterial overgrowth, including species able to deconjugate bile salts, was not always associated with increased excretion of fat.

This work was supported by the Board of Governors, St Bartholomew's Hospital.

\section{REFERENCES}

BADENOCH, J. 1958. The blind loop syndrome. In Modern trends in gastroenterology, edited by F. A. Jones, London, pp. 231-242.

Bockus, H. L. 1964. Regional enteritis. In Gastroenterology, Philadelphia, vol. 2, pp. 226310.

Cameron, D. G., Watson, G. M., AND Witts, L. J. 1949. The clinical association of macrocytic anaemia with intestinal stricture or anastomosis. Blood, 4, 793.

Donaldson, R. M., JR 1964. Normal bacterial populations of the intestine and their relation to intestinal function. New Engl. J. Med., 270, 938.

Drasar, B. S., AND ShIner, Margot 1969. Studies on the intestinal flora: II Bacterial flora of the small intestine in patients with gastrointestinal disorders. Gut, 10, 812.

Drasar, B. S., Shiner, Margot, and McLeod, G. M. 1969. Studies on the intestinal flora: I. The bacterial flora of the gastrointestinal tract in healthy and achlorhydric persons. Gastroenterology, 56, 71.

Gorbach, S. L., Banwell, J. G., Mitra, R., Chatterjee, B. D., Jacobs, B., and Mazumder, D. N. G. 1969. Bacterial contamination of the upper small bowel in tropical sprue. Lancet, $1,74$.

Gorbach, S. L., Plaut, A. G., Nahas, L., Weinstein, L., Spanknebel, G., and Levitan, R. 1967. Studies of intestinal flora: II Microorganisms of the small intestine and their relation to oral and fecal flora. Gastroenterology, 53, 856.

Hamilton, J. D., Dyer, N. H., Dawson, A. M., O'Grady, F. W., Vince, A., Fenton, J. C. B., AND Mollin, D. L. 1970. Assessment and significance of bacterial overgrowth in the small bowel. Quart. J. Med., n.s. 39, 265. 
Heinle, R. W., Welch, A. D., Scharf, V., Meacham, G. C., and Prusoff, W. H. 1952. Studies of excretion and absorption of Co60-labeled vitamin $\mathrm{B}_{12}$ in pernicious anemia. Trans. Assoc. Amer. Physns., 65, 214.

Jones, E. A., Craigie, A., Tavill, A. S., Franglen, G., and Rosenoer, V. M. 1968. Protein metabolism in the intestinal stagnant loop syndrome. Gut, 9, 466.

Kamer, J. H. van de, ten BokKel Huinink, H., AND Weyers, H. A. 1949. Rapid method for the determination of fat in feces. J. Biol. Chem., 177, 347.

Mollin, D. L., Booth, C. C., AND BAKeR, S. J. 1957. The absorption of vitamin $\mathbf{B}_{12}$ in control subjects in Addisonian pernicious anaemia and in the malabsorption syndrome. Br. J. Haemat., 3, 412.

O'Grady, F., AND VINCE, A. 1971. Clinical and nutritional significance of intestinal bacterial overgrowth. J. Clin. Path., 24, Suppl. (Roy. Coll. Path.) 5, 130.

Patter, W. N. van, Bargen, J. A., Dockerty, M. B., Feldman, W. H., Mayo, C. W., and WAUGH, J. M. 1954. Regional enteritis. Gastroenterology, 26, 347.

Paulk, E. A., JR, AND Farrar, W. E., JR 1964. Diverticulosis of the small intestine and megaloblastic anemia. Intestinal microflora and absorption before and after tetracycline administration. Amer. J. Med., 37, 473.

Schilling, R. F. 1953. Intrinsic factor studies. II. The effect of gastric juice on the urinary excretion of radioactivity after the oral administration of radioactive vitamin $\mathbf{B}_{12}$. J. Lab. Clin. Med., 42, 860.

Shiner, Margot, Waters, T. E., AND Gray, J. D. A. 1963. Culture studies of the gastrointestinal tract with a newly devised capsule. Gastroenterology, 45, 625.

TABaQChali, S., AND Booth, C. C. 1967. Relationship of the intestinal bacterial flora to absorption. Br. Med. Bull., 23, 285.

Tabaqchali, S., Okubadejo, O. A., Neale, G., and Booth, C. C. 1966. Influence of abnormal bacterial flora on small intestinal function. Proc. Roy. Soc. Med., 59, 1244.

Tabaqchali, S., Hatzionnou, J., and Booth, C. C. 1968. Bile salt deconjugation and steatorrhoea in patients with the stagnant-loop syndrome. Lancet, 2, 12. 